\title{
Phenotype-specific inhibition of the vascular smooth muscle cell cycle by high glucose treatment
}

\author{
X.-L. Zheng • S.-G. Yuan • D.-Q. Peng
}

Received: 20 July 2006 / Accepted: 14 October 2006 / Published online: 14 February 2007

(C) Springer-Verlag 2007

\begin{abstract}
Aims/hypothesis Diabetes accelerates the development of atherosclerosis, which critically involves the proliferation of vascular smooth muscle cells (SMCs). However, how high glucose treatment regulates SMC proliferation is controversial. Considering the established SMC heterogeneity, we hypothesised that glucose treatment may have distinct effects on proliferation of the various phenotypic SMCs. Materials and methods We tested this possibility using cloned spindle-shaped and epithelioid SMCs and laser scanning cytometry.

Results Our results showed that glucose treatment significantly inhibited the serum-independent proliferation of epithelioid SMCs, but had no effect on the proliferation of spindle-shaped cells either with or without serum stimulation. Furthermore, glucose treatment inhibited DNA synthesis, as detected by bromodeoxyuridine (BrdU) incorporation, and increased the production of reactive oxygen species in epithelioid SMCs. The inhibition of BrdU incorporation by glucose treatment was mimicked by glucosamine and phorbol 2,13-dibutyrate, a protein kinase $\mathrm{C}$ (PKC) activator, and reversed by azaserine, an inhibitor of the hexosamine pathway. In addition, the inhibitory effects of glucose treatment were blocked by GF 109203X (a PKC inhibitor) and PD98058 (a MAPK/ERK kinase, MEK inhibitor), and by knockdown of MEK1 by small interfering RNA (siRNA). The addition of either GF
\end{abstract}

\footnotetext{
X.-L. Zheng $(\bowtie) \cdot$ S.-G. Yuan $\cdot$ D.-Q. Peng

Smooth Muscle Research Group, Department of Biochemistry and Molecular Biology, Faculty of Medicine,

University of Calgary Health Sciences Centre,

3330 Hospital Drive NW,

Calgary, AB T2N 4N1, Canada

e-mail: xlzheng@ucalgary.ca
}

109203X or PD98058 also reduced the phosphorylation of MAP kinase induced by glucose treatment.

Conclusions/interpretation Glucose treatment inhibits the proliferation of epithelioid, but not spindle-shaped, vascular SMCs through the activation of PKC and the MAP kinase pathway, suggesting that the effects of hyperglycaemia on vascular disease depend on the phenotype of SMCs involved.

Keywords Cell cycle $\cdot$ High glucose $\cdot$ Smooth muscle cells . SMC heterogeneity

$\begin{array}{ll}\begin{array}{l}\text { Abbreviations } \\ \text { BrdU }\end{array} & \\ \text { carboxy- } & \begin{array}{l}\text { bromodeoxyuridine } \\ \text { 5-(and -6)-carboxy-2',7'-dichlorodihydro- } \\ \text { fluorescein diacetate } \\ \text { epidermal growth factor }\end{array} \\ \text { EGF } & \text { epidermal growth factor receptor } \\ \text { EGFR } & \text { laser scanning cytometry } \\ \text { LSC } & \text { mitogen-activated protein } \\ \text { MAP } & \text { MAPK/ERK kinase } \\ \text { MEK } & \text { phorbol 2,13-dibutyrate } \\ \text { PDBu } & \text { protein kinase C } \\ \text { PKC } & \text { reactive oxygen species } \\ \text { ROS } & \text { small interfering RNA } \\ \text { siRNA } & \text { smooth muscle cells } \\ \text { SMCs } & \end{array}$

\section{Introduction}

Atherosclerosis is a proliferative vascular disease that critically involves the proliferation of vascular smooth muscle cells (SMCs) [1,2]. Diabetes is known to accelerate the development of atherosclerosis. Therefore, it is impor- 
tant to address whether direct effects of hyperglycaemia on SMC proliferation contribute to diabetic atherosclerosis. The way in which glucose treatment regulates the proliferation of vascular SMCs is still controversial: some studies have shown that glucose treatment stimulates the proliferation of cultured vascular SMCs [3-10], but others have shown that glucose treatment does not have such an effect [11-14]. In vivo studies examining the proliferative response of medial and intimal cells in carotid arteries after balloon injury in rat models of type 1 and type 2 diabetes showed increased cell proliferation in type 2 diabetic obese Zucker rats, but not in streptozotocin-induced type 1 diabetic rats [15]. In a porcine model of diabetes-accelerated atherosclerosis, diabetes was shown to accelerate smooth muscle cell accumulation in atherosclerotic lesions, but glucose treatment did not have direct growth-promoting effects [16]. These data suggest that hyperglycaemia alone does not stimulate arterial cell proliferation. Interestingly, other studies have shown that balloon injury of arteries in type 1 diabetic rats [17, 18] or rabbits [19] results in decreased DNA synthesis, as shown by bromodeoxyuridine (BrdU) incorporation in SMCs compared with non-diabetic controls, suggesting that hyperglycaemia inhibits the proliferation of vascular SMCs. However, the underlying cellular and molecular mechanisms are not completely understood.

The heterogeneity of vascular SMCs has been well established in many species, including humans (reviewed in [20]). This concept suggests that the blood vessel wall contains multiple SMC phenotypes, which may play distinct roles in the development of atherosclerosis and restenosis after angioplasty. Two phenotypes are present in cultured vascular SMCs [21]: spindle-shaped and epithelioid. Epithelioid SMCs have higher proliferation and migration activities [20]. Because these activities are critical in atherogenesis and cells derived from neointima lesions demonstrate an epithelioid phenotype, epithelioid SMCs have been considered to be candidates for 'atheroma-prone' cells. Importantly, increasing evidence has demonstrated the phenotype-specific effects of vasoactive agents, such as epidermal growth factor (EGF) [22]. Therefore, it is conceivable that glucose treatment has phenotype-specific effects on the proliferation of vascular SMCs. In the present study we investigated this possibility and the underlying mechanisms.

\section{Materials and methods}

D-glucose, D-mannitol, glucosamine, azaserine, phorbol 2,13-dibutyrate (PDBu), GF 109203X, AG1478, PD98059, bromodeoxyuridine (BrdU), propidium iodide (PI) and mouse monoclonal antibodies for smooth muscle $\alpha$-actin and $\alpha$-tubulin were obtained from Sigma-Aldrich Canada Ltd (Oakville, ON, Canada). Anti-mitogen-activated protein (MAP) kinase antibody was obtained from Calbiochem. Anti-p27 antibody and the antibody specific for phospho-p42/44 were from Cell Signaling Technology, Inc. (Danvers, MA, USA). Human recombinant EGF was purchased from UBI (Lake Placid, NY, USA). The antiBrdU antibody and anti-mouse and anti-rabbit secondary antibodies labelled with Alexa Fluor 488 or 647 and 5(and-6)-carboxy-2',7'-dichlorodihydrofluorescein diacetate (carboxy-H2DCFDA) were purchased from Molecular Probes (Eugene, OR, USA). Cell culture medium, RPMI 1640 and fetal bovine serum were from Invitrogen Canada Inc. (Burlington, ON, Canada). M. Walsh generously provided us with anti-h1-calponin antibody. MEK1 antibody was from Abcam Inc. (Cambridge, MA, USA). MEK1 SMARTpool small interfering RNA (siRNA) (L091067-00) and non-specific control siRNA were purchased from Dharmacon (Lafayette, CO, USA). Trans-IT TKO transfection reagent was from Mirus (Madison, WI, USA).

Cloning of primary cultured SMCs and treatments Primary culture of rat aortic SMCs and cloning of two SMC phenotypes were performed as described previously [22]. Briefly, thoracic aortic tissues for primary cell culture were derived from male Sprague-Dawley rats (250-300 g), which were purchased from Charles River Laboratories (Senneville, QC, Canada). The animal use protocol was approved by the Animal Use and Care Committee at the University of Calgary. The tissue was cut into small pieces $\left(1 \mathrm{~mm}^{3}\right)$ for explantation, and the explanted tissues were maintained in RPMI 1640 medium containing 10\% (v/v) fetal bovine serum. SMCs were verified by detection of several differentiation marker proteins, such as smooth muscle $\alpha$ - and h1-calponin. Spindle-shaped and epithelioid SMCs were cloned using a limiting dilution cloning method as described [23]. Cloned cells were distinguished by their typical morphologies. Epithelioid, but not spindle-shaped, SMCs were further verified by their serum-independent cell growth. For cell starvation, cultured cells were maintained in medium containing $0.5 \%$ serum for 2 days. Cells were treated with glucose $(25 \mathrm{mmol} / \mathrm{l})$ with or without various pretreatments as indicated in the text.

Staining for incorporated BrdU in the nuclei SMCs cultured on coverslips were labelled with $\operatorname{BrdU}(10 \mu \mathrm{mol} / 1)$, a thymidine analogue, at $37^{\circ} \mathrm{C}$ for $60 \mathrm{~min}$, followed by fixation and staining with anti-BrdU monoclonal antibody and a secondary antibody conjugated with Alexa Fluor 647 (Molecular Probes). The nuclei were counterstained with PI ( $5 \mu \mathrm{g} / \mathrm{ml}$ containing $200 \mu \mathrm{g} / \mathrm{ml}$ RNase), which was followed by laser scanning cytometry (LSC) analysis [24]. 
LSC DNA analysis and studies of BrdU incorporation in response to various treatments were performed using LSC (CompuCyte, Cambridge, MA, USA) as described previously [25]. Briefly, cell monolayers were grown on coverslips and immunostained with anti-BrdU antibody and Alexa Fluor 647-conjugated secondary antibody, followed by counterstaining with PI for nuclear DNA as described above. Cells mounted on microscopic slides were located visually with a CCD camera attached to the LSC instrument. Detailed information on the LSC method has been published elsewhere [26]. Slides were scanned under $\times 20$ objectives using both argon and helium lasers to excite the PI and Alexa Fluor 647 fluorochromes. Each slide was scanned randomly for three fields, and at least 1,000 cells in each field were scanned. The scanning data were acquired and analysed with WinCyte acquisition software (version 3.4; CompuCyte). The software displayed multiple data parameters in a series of data windows. We contoured each nucleus as a single event by PI staining as previously described $[25,26]$. All scanned cells were used to generate the DNA histograms and the scattergrams for BrdU incorporation. The BrdU-positive cells were shown to have more total fluorescence in their nuclei, as demonstrated in the scattergram of total fluorescent intensity (Alexa Fluor 647 integral) vs total DNA content (PI integral). Since DNA content reflects the position in the cell cycle, we were able to observe cells in different cell cycle phases by measuring their DNA content. Therefore, cells, after labelling with BrdU, could be monitored for their movement in the cell cycle by measurement of incorporated BrdU.

Determination of cell growth Cells were seeded in 35-mm Petri dishes with $0.5 \times 10^{5}$ cells in each and cultured with medium containing $10 \%$ serum for $24 \mathrm{~h}$. Cells were then maintained in medium containing $0.5 \%$ serum for 2 days, followed by treatment with or without glucose for an additional 3 days. Thereafter, cells were harvested and counted using a haemocytometer.

Knockdown of MEK1 by siRNA Cells were transfected with $100 \mathrm{nmol}$ of either MEK1 SMARTpool siRNA (L-09106700) or non-specific control siRNA using Trans-IT TKO transfection reagent according to the protocols recommended by the manufacturers. Knockdown of MEK1 was confirmed by western blotting. BrdU incorporation of transfected cells with and without high-glucose treatment was analysed using LSC.

Western blot analysis SMCs grown in 100-mm Petri dishes were lysed after various treatments, followed by protein extraction as described previously [22]. Equal amounts of protein from each sample $(40 \mu \mathrm{g})$ were separated by $11 \%$ SDS-PAGE and transferred to nitrocellulose membranes.
Antibodies against total p42/44 MAP kinase, phosphospecific p42/44 MAP kinase, p27kip1 and MEK1 were used as primary antibodies to detect their respective proteins. Horseradish peroxidase-coupled secondary antibodies (1:2,500 dilution) were used with the ECL Detection Kit (Amersham Canada, Oakville, ON, Canada) as described previously [27].

Detection of reactive oxygen species After treatment with and without glucose for $24 \mathrm{~h}$, cells were loaded with carboxy-H2DCFDA $(10 \mu \mathrm{mol} / \mathrm{l})$ for $60 \mathrm{~min}$, followed by $40 \mathrm{~min}$ recovery. Cells were then trypsinised and resuspended in PBS containing 4'-6-diamidino-2-phenylindole (DAPI; $5 \mu \mathrm{g} / \mathrm{ml}$ ). Ten microlitres of cell suspension from each sample was mounted on the microscope slide and fluorescence intensity was determined using LSC, as described previously for flow cytometry $[28,29]$.

Data analysis Data are presented as the mean \pm SEM. The number of replicates $(n)$ is the number of cell samples used in the studies. Differences between means were evaluated by Student's $t$ test (paired or independent) when two groups were compared, and by ANOVA followed by Bonferroni's correction when three or more groups were compared, using InStat3 (GraphPad, San Diego, CA, USA). $p<0.05$ was considered significant.

\section{Results}

Glucose treatment inhibits the proliferation of epithelioid SMCs To test whether glucose treatment has phenotypespecific effects on vascular SMCs, we cloned spindle-shaped and epithelioid SMCs from primary cultures of rat aortic SMCs, as shown in Fig. 1a,b, respectively. As shown in Fig. 1c, epithelioid SMCs underwent serum-independent growth, and these cells had a higher production level of epidermal growth factor receptor (EGFR) compared with spindle-shaped cells, as we have described previously [22]. To examine the effects of glucose treatment, we cultured both epithelioid and spindle-shaped SMCs in starvation medium containing $0.5 \%$ serum for $24 \mathrm{~h}$. Cells were then treated with or without $25 \mathrm{mmol} / \mathrm{l} \mathrm{D}$-glucose or equimolar D-mannitol for 3 days, followed by cell counting using a haemocytometer. The control cells were maintained in the regular medium containing $5 \mathrm{mmol} / \mathrm{l}$ glucose. The results in Fig. 1d show that the treatment with $25 \mathrm{mmol} / \mathrm{l}$ D-glucose, but not D-mannitol, significantly inhibited the proliferation of epithelioid SMCs. However, high-glucose treatment did not stimulate or inhibit the proliferation of spindle-shaped SMCs in absence of serum (Fig. 1e) or in the presence of serum (data not shown). Therefore, we focused on our studies in epithelioid SMCs. 
a

Spindle-shaped SMCs

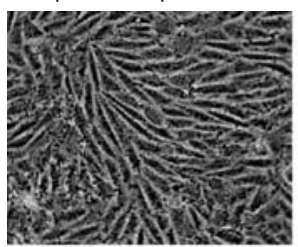

C

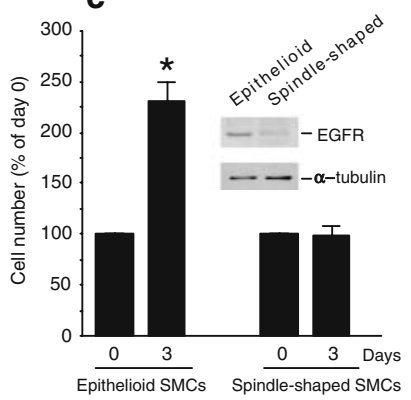

b

Epithelioid SMCs

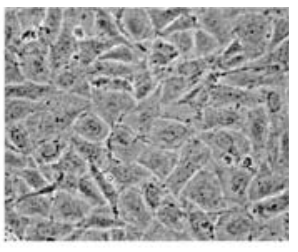

d
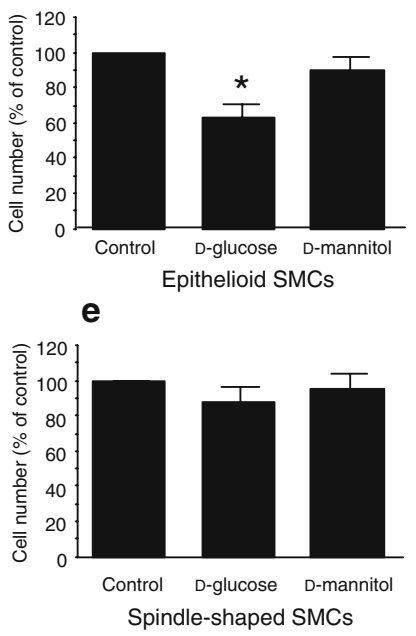
Epithelioid SMCs

Fig. 1 Glucose treatment inhibits the serum-independent proliferation of epithelioid, but not spindle-shaped, SMCs cloned from rat aortic primary cell culture. Spindle-shaped and epithelioid SMCs were cloned from primary cultured rat aortic SMCs as described in Materials and methods. $\mathbf{a}$ and $\mathbf{b}$ Micrographs taken under conventional inverted microscopy for spindle-shaped and epithelioid SMCs, respectively. c Epithelioid, but not spindle-shaped, SMCs proliferated in starvation medium $(0.5 \%$ serum $)$. Insert shows representative western blots of EGFR and $\alpha$-tubulin. $\mathbf{d}$ and e Summarised data on cell number in the presence or absence of D-glucose and D-mannitol for epithelioid and spindle-shaped SMCs, respectively. Significant difference compared with control ( $5 \mathrm{mmol} / 1$ glucose): ${ }^{*} p<0.05, n=4$

Glucose treatment inhibits DNA synthesis and increases production of ROSs in epithelioid SMCs, and glucosamine mimics the effect of glucose treatment Glucose treatment inhibited the proliferation of epithelioid SMCs in the absence of $10 \%$ serum. Therefore, we used LSC to analyse the cell cycle profile of the cells treated or not treated with glucose. Our results showed that glucose treatment caused cell accumulation in the G0/1 phase with a significant decrease in the number of cells in the $\mathrm{S}$ phase (Table 1), suggesting inhibition of cell entry into $\mathrm{S}$ phase. We therefore examined DNA synthesis as indicated by BrdU incorporation rate. To do this, cells were first starved in medium containing $0.5 \%$ serum for $48 \mathrm{~h}$ and then treated with $25 \mathrm{mmol} / \mathrm{l} \mathrm{D}$-glucose for $24 \mathrm{~h}$. After treatment, cells were pulse-labelled with $\mathrm{BrdU}$ for $60 \mathrm{~min}$ and the incorporated BrdU was detected and analysed using LSC, as described in Materials and methods. In Fig. 2, panels a-c are representative scattergrams of LSC data showing inhibition of BrdU incorporation by glucose treatment. The summarised data indicate that glucose treatment significantly inhibited the incorporation of $\mathrm{BrdU}$ by epithelioid SMCs (Fig. 2d). In addition, glucose treatment significantly increased the production of reactive oxygen species (ROS), as detected by LSC (Fig. 2e). Similar results were obtained in three independent experiments.

In addition, we examined the effects of glucosamine, a glucose metabolite and product of the hexosamine pathway, because it mimics certain effects of glucose on vascular SMCs, such as the stimulation of growth factor gene expression [30, 31]. Our results showed that glucosamine ( $7.5 \mathrm{mmol} / \mathrm{l})$ mimicked the effects of glucose treatment on the cell cycle profile (Table 1) and BrdU incorporation in epithelioid SMCs (Fig. 2), suggesting that the effects of glucose acted through the formation of glucosamine. To confirm this, we pretreated cells with azaserine $(5 \mu \mathrm{mol} / \mathrm{l})$, an inhibitor of glutamine:fructose-6-phosphate aminotransferase before addition of glucose and then measured BrdU incorporation in epithelioid SMCs. Our results showed that azaserine reversed the inhibition of BrdU incorporation by glucose treatment but had no effect on glucosamineinduced inhibition (Fig. 2f). These results suggested involvement of the hexosamine pathway in the phenotypespecific effects of glucose treatment on SMCs.

The PKC inhibitor GF $109203 X$ inhibits the effects of glucose treatment and glucosamine Glucose treatment and glucosamine are known to stimulate PKC to contribute to glucose toxicity in the vascular system [32]. It is possible, therefore, that PKC inhibition will block the effects of glucose treatment and glucosamine. To this end, we examined the effects of GF 109203X, an inhibitor of PKC [33]. Our results showed that, in the presence of GF 109203X, treatment with glucose or glucosamine did not significantly inhibit BrdU incorporation (Fig. 3). This suggested that activation of PKC mediates the effects of glucose and glucosamine. To seek more evidence to support this hypothesis, we examined whether activation of PKC using a PKC activator, PDBu (1 $\mu \mathrm{mol} / \mathrm{l})$, inhibited the

Table 1 Cell cycle profiles of epithelioid SMCs in response to treatment with glucose or glucosamine ( $\%$ of total cells)

\begin{tabular}{llll}
\hline & $\begin{array}{l}\text { G0/1 } \\
(\text { gap 0/1) }\end{array}$ & S (synthesis) & $\begin{array}{l}\text { G2/M } \\
\text { (gap 2/mitosis) }\end{array}$ \\
\hline Normal glucose & $65 \pm 4$ & $28 \pm 4$ & $7 \pm 3$ \\
High glucose & $81 \pm 4^{\mathrm{a}}$ & $15 \pm 3^{\mathrm{a}}$ & $4 \pm 2$ \\
Glucosamine & $91 \pm 5^{\mathrm{a}}$ & $5 \pm 2^{\mathrm{a}}$ & $4 \pm 3$ \\
\hline
\end{tabular}

${ }^{\text {a }}$ Significant difference compared with the group with normal glucose concentration $(p<0.05, n=5)$ 


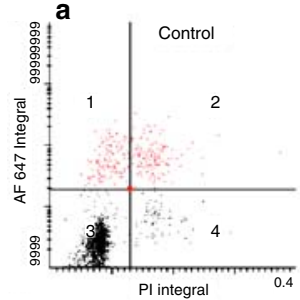
c
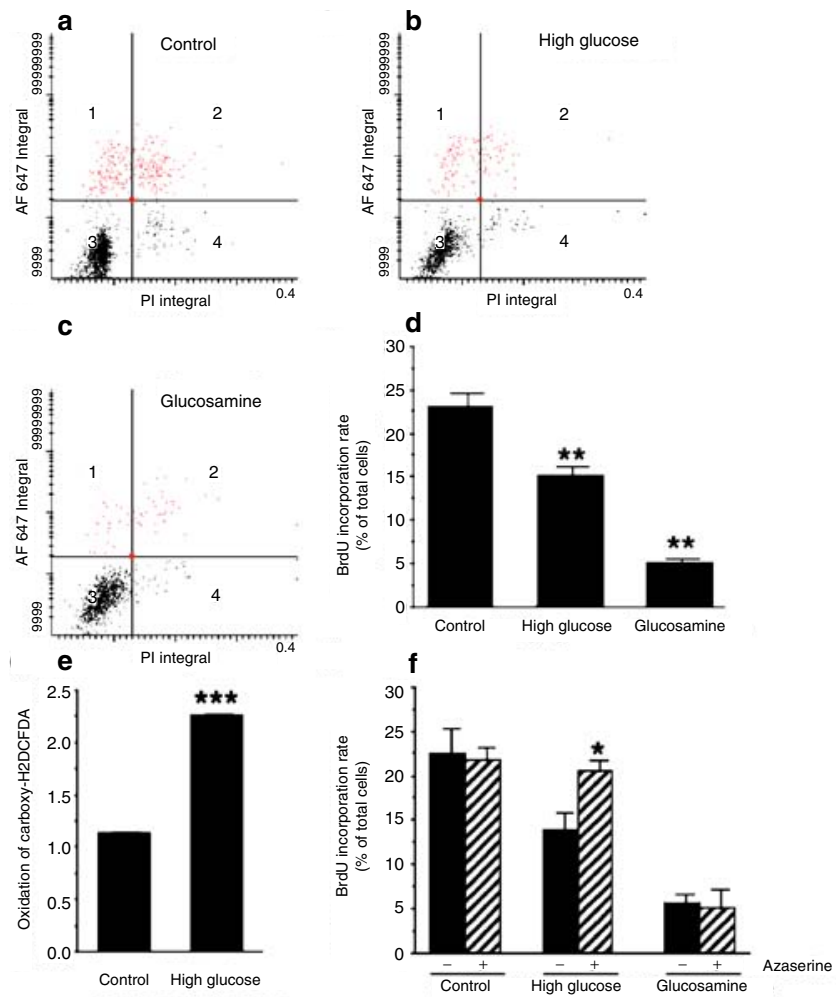

Fig. 2 Treatment with glucose and glucosamine inhibits DNA synthesis in epithelioid smooth muscle cells (SMCs). Cells were starved using medium containing $0.5 \%$ serum for 2 days, followed by treatment with or without D-glucose $(25 \mathrm{mmol} / \mathrm{l})$ or glucosamine ( $7.5 \mathrm{mmol} / \mathrm{l})$ for $24 \mathrm{~h}$. Cells were then labelled with $\operatorname{BrdU}(10 \mu \mathrm{mol} / \mathrm{l})$ for $60 \mathrm{~min}$, followed by staining for BrdU and LSC analysis as described in Materials and methods. a-c Representative scattergrams of LSC scanning data. The $y$-axis shows the total florescence in each cell, indicating the amount of $\operatorname{BrdU}$ (a, control; b, high glucose; c, glucosamine). The $x$-axis shows the total amount of DNA in each scanned cell, indicated by the total fluorescence intensity of PI. Cells in quadrants 1 and 2 are considered BrdU-positive. d Summarised data for various treatments. The $y$-axis shows the BrdU incorporation rate of scanned cells. Significant difference compared with control: $* * p<0.01, n=3$. e Oxidation of carboxy-H2DCFDA as indicated by fluorescence intensity in control cells and cells treated with glucose (500 cells scanned for each sample). Significant difference compared with control: $* * * p<0.001$. f Summarised data showing that azaserine reverses the inhibition of BrdU incorporation rate by glucose treatment. Significant difference compared with control: ${ }^{*} p<0.05, n=4$

incorporation of BrdU in epithelioid cells and mimicked the effects of glucose treatment and glucosamine. As expected, $\mathrm{PDBu}$ treatment significantly inhibited incorporation of BrdU by epithelioid SMCs (Fig. 4). Importantly, our results showed that GF 109203X was also able to inhibit the effect of PDBu. Taken together, our data showed that glucose treatment and glucosamine inhibited BrdU incorporation in epithelioid SMCs in a phenotype-specific manner through activation of the PKC pathway.

The MEK inhibitor PD98059 blocks the inhibition of BrdU incorporation by $P D B u$, glucose and glucosamine Previous

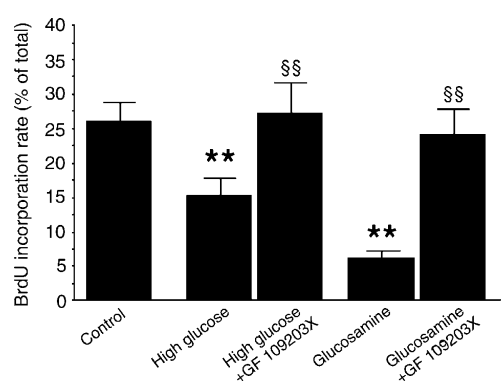

Fig. 3 The PKC inhibitor GF 109203X prevents the inhibitory effects of glucose and glucosamine on DNA synthesis. Cells were starved for 2 days using medium containing $0.5 \%$ serum as described in Materials and methods, then treated with D-glucose $(25 \mathrm{mmol} / \mathrm{l})$ or glucosamine ( $7.5 \mathrm{mmol} / \mathrm{l})$ for $24 \mathrm{~h}$ with or without pretreatment with GF $109203 \mathrm{X}$ for $30 \mathrm{~min}$. Before fixation, cells were labelled with $10 \mu \mathrm{mol} / 1 \mathrm{BrdU}$ for $60 \mathrm{~min}$, and were then stained for BrdU and LSC analysis as described in Materials and methods. The $y$-axis shows the BrdU incorporation rate of scanned cells. Significant difference compared with control: $* * p<0.01, n=4$. Significant difference compared with cells treated with glucose or glucosamine: ${ }^{\S \S} p<0.01, n=4$

studies have shown that activation of PKC inhibits the proliferation of SMCs [34-36]. In epithelioid SMCs, activation of the PKC pathway by PDBu and glucosamine or glucose treatment results in inhibition of cell proliferation. In the same system, we have previously shown that activation of the MAP kinase pathway by EGF inhibits the proliferation of epithelioid SMCs [22]. This raises the possibility that PKC inhibition of cell proliferation acts through activation of the MAP kinase pathway.

It is well known that PKC phosphorylates and stimulates RAF kinase in the MAP kinase pathway [37-40]. Therefore, we tested whether inhibition of MEK downstream of RAF by the MEK inhibitor PD98059 prevents the inhibition of BrdU incorporation in response to treatment with $\mathrm{PDBu}$, glucose or glucosamine. Our results showed that treatment with PD98059 prevented the inhibition of

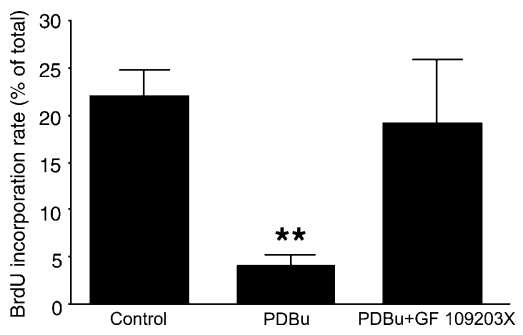

Fig. 4 Phorbol 2,13-dibutyrate $(P D B u)$ inhibits DNA synthesis and this effect is inhibited by GF 109203 X. Cells were starved for 2 days using medium containing $0.5 \%$ serum as described in Materials and methods. Then cells were treated with PDBu $(1 \mu \mathrm{mol} / \mathrm{l})$ for $24 \mathrm{~h}$ with or without pretreatment with GF $109203 \mathrm{X}$ for $30 \mathrm{~min}$. At the end of treatment, cells were labelled with $10 \mu \mathrm{mol} / 1 \mathrm{BrdU}$ for $60 \mathrm{~min}$, followed by staining and LSC analysis as described in Materials and methods. The $y$-axis shows the BrdU incorporation rate of scanned cells. Significant difference compared with control: $* * p<0.01, n=4$ 


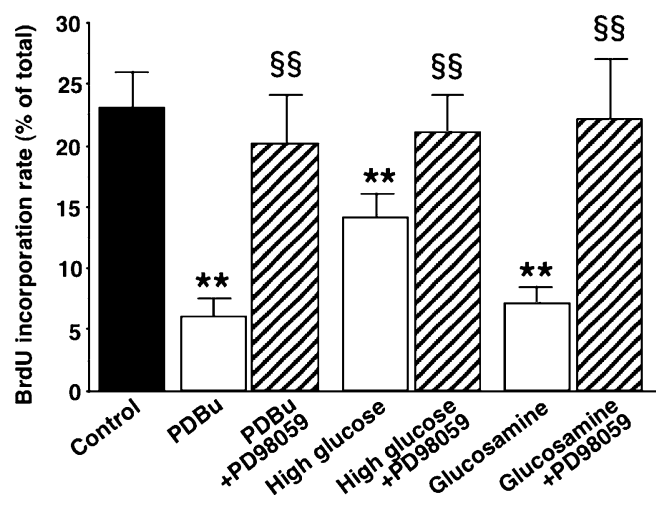

Fig. 5 The MEK inhibitor PD98059 inhibits the effects of glucose, glucosamine and $\mathrm{PDBu}$ on DNA synthesis in epithelioid smooth muscle cells. Cells were maintained in medium containing $0.5 \%$ serum for 2 days and then treated with $\mathrm{PDBu}(1 \mu \mathrm{mol} / \mathrm{l})$, D-glucose $(25 \mathrm{mmol} / \mathrm{l})$ or glucosamine $(7.5 \mathrm{mmol} / \mathrm{l})$ for $24 \mathrm{~h}$ with or without pretreatment with PD98059 for $30 \mathrm{~min}$. Cells were then labelled with $\mathrm{BrdU}(10 \mu \mathrm{mol} / \mathrm{l})$ for $60 \mathrm{~min}$. The incorporated BrdU was stained and analysed using LSC as described in Materials and methods. The $y$-axis shows the BrdU incorporation rate of scanned cells summarised from LSC scattergrams. Significant difference compared with control: ${ }^{* *} p<0.01, n=4$. Significant difference compared with cells treated with $\mathrm{PDBu}$, high glucose or glucosamine alone: ${ }^{\S \S} p<0.01, n=4$

BrdU incorporation induced by glucose, glucosamine or PDBu (Fig. 5).

To further establish the role of this pathway, we used siRNA to knock down MEK1 in epithelioid SMCs and then determined the effects of glucose treatment. Our data a

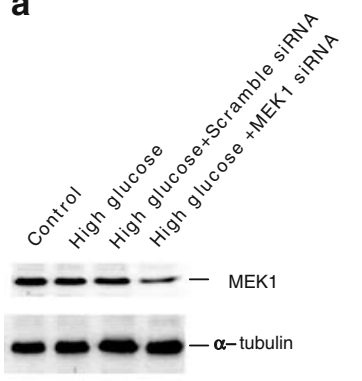

b

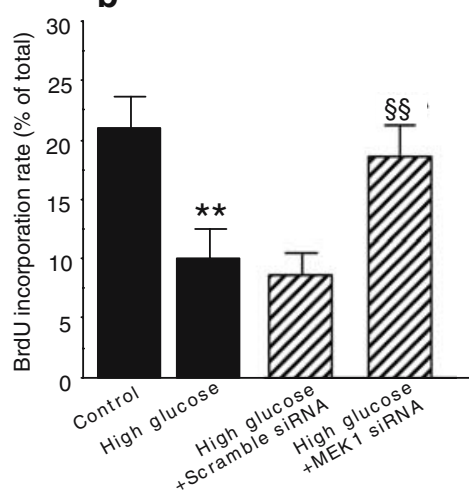

Fig. 6 Knockdown of MEK1 by siRNA reverses glucose inhibition of DNA synthesis. Epithelioid smooth muscle cells were cultured using medium containing $10 \%$ serum, transfected with MEK1 siRNA or control siRNA as described in Materials and methods. After transfection for $48 \mathrm{~h}$, cells were treated or not treated with glucose for $24 \mathrm{~h}$ in the presence of starvation medium, followed by BrdU labelling for $60 \mathrm{~min}$ and LSC analysis or protein extraction and western blot analysis. a Representative western blots to detect MEK1 and $\alpha$-tubulin. b BrdU incorporation by smooth muscle cells transfected with and without MEK1 siRNA or control siRNA. The $y$-axis shows the BrdU incorporation rate of scanned cells summarised from LSC scattergrams. Significant difference compared with control: $* * p<0.01$. Significant difference compared with high-glucose treatment alone: ${ }^{\S} p<0.01$
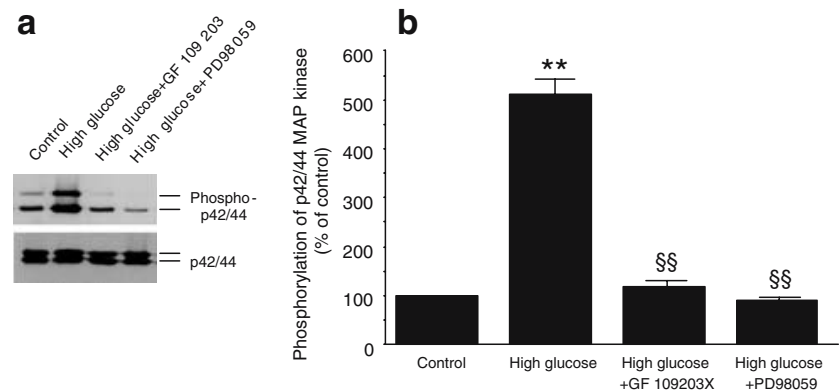

Fig. 7 Glucose treatment activates p42/44 MAP kinase and this stimulation is inhibited by PD98059 and GF 109203X. Cells were starved using medium containing $0.5 \%$ serum for 2 days, and then treated with D-glucose $(25 \mathrm{mmol} / \mathrm{l})$ for $15 \mathrm{~min}$ with or without pretreatment with PD98059 $(10 \mu \mathrm{mol} / \mathrm{l})$ or GF $109203(1 \mu \mathrm{mol} / \mathrm{l})$ for $30 \mathrm{~min}$. Thereafter, cells were lysed for protein extraction and western blot detection of total and phosphorylated p42/44 MAP kinase as described in Materials and methods. a Representative western blot showing phosphorylated p42/44 and total p42/44 MAP kinases. b Summarised data from three independent experiments. The $y$-axis represents relative MAP kinase activities derived from densitometry compared with control. Significant difference compared with control: $* * p<0.01, n=3$. Significant difference compared with cells treated with D-glucose alone: ${ }^{\S} p<0.01, n=3$

showed that siRNA transfection significantly reduced the level of MEK1, with a reduction of $75 \pm 5 \%$ compared with the cells transfected with control siRNA $(n=3, p<0.01)$. Figure $6 \mathrm{a}$ shows the representative western blots. As expected, inhibition of DNA synthesis by glucose treatment, as indicated by BrdU incorporation, was significantly reversed by the transfection of MEK1 siRNA, but not control siRNA (Fig. 6b). All data have suggested involve-
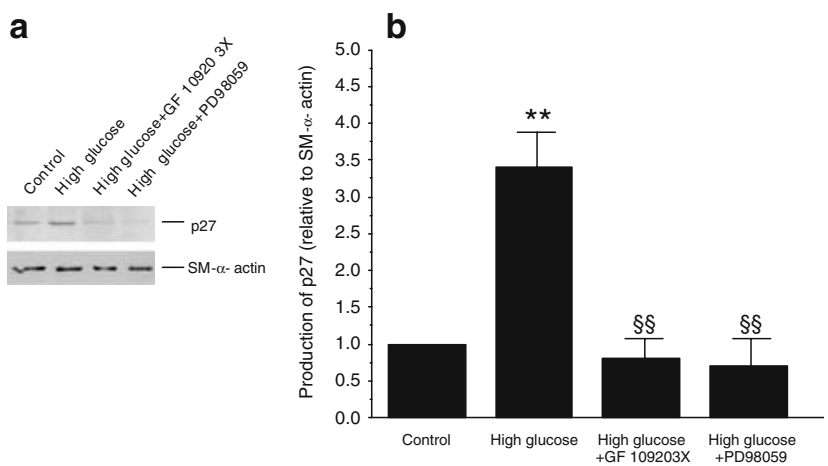

Fig. 8 Glucose treatment induces the production of p27. Cells were starved using medium containing $0.5 \%$ serum for $24 \mathrm{~h}$, then treated with D-glucose $(25 \mathrm{mmol} / \mathrm{l})$ for 2 days in the presence or absence of PD98059 $(10 \mu \mathrm{mol} / \mathrm{l})$ or GF $109203(1 \mu \mathrm{mol} / \mathrm{l})$. Cells were lysed for protein extraction and western blot detection of p27 and smooth muscle $\alpha$-actin as described in Materials and methods. a Representative western blot showing the production of p27 and smooth muscle $\alpha$-actin. b Summarised data from three independent experiments. The abundance of $\mathrm{p} 27$ is shown relative to smooth muscle $\alpha$-actin based on the densitometry measurements. Significant difference compared with control: $* * p<0.01, n=3$. Significant difference compared with cells treated with D-glucose alone: ${ }^{\S} p<0.01, n=3$ 
ment of the MAP kinase pathway in high glucose-induced inhibition of SMC proliferation.

In addition, one study reported that glucose treatment enhances transactivation of EGFR by G-protein-coupled receptor agonists, such as angiotensin II, suggesting a potential role of EGFR in the effects of glucose treatment [41]. Because our previous studies had shown that activation of EGFR activates the MAP kinase pathway, resulting in cell cycle arrest in epithelioid SMCs [22], we examined whether inhibition of EGFR would change the effects of glucose treatment. Therefore, we pretreated cells with AG1478 and then determined the effects of glucose treatment. However, we did not observe any change in the effects of glucose treatment on BrdU incorporation (data not shown).

High glucose stimulates the phosphorylation of p42/44 MAP kinases Our previous studies have shown that activation of the MAP kinase pathway inhibits the cell cycle of epithelioid SMCs with upregulation of p27 [22]. To confirm that the observed effects of glucose treatment also act through this mechanism, we examined whether glucose treatment indeed stimulates the MAP kinase pathway. To do this, we chose to measure the phosphorylation of the p42/44 MAP kinases with or without glucose treatment. Our results showed that glucose treatment for 15 min stimulated the p42/44 MAP kinases, as indicated by an increase in their phosphorylation (Fig. 7). Importantly, our results also showed that pretreatment with either the MEK inhibitor PD98059 or the PKC inhibitor GF 109203X prevented p42/44 phosphorylation. Furthermore, we examined the production of p27 in response to glucose treatment. Our results showed that the glucose treatment increased the level of p27 (Fig. 8) and that the MEK inhibitor PD98059 or the PKC inhibitor GF 109203X prevented the increase in p27.

\section{Discussion}

Taken together, our results reveal that glucose treatment selectively inhibits the proliferation of epithelioid SMCs, and that the mechanism underlying this phenotype-specific effect involves the hexosamine pathway, activation of PKC and subsequent stimulation of the MAP kinase pathway. This study may provide insight into the direct effects of hyperglycaemia on vascular SMCs in the pathogenesis of vascular complications in diabetes.

First, our data showing that glucose treatment inhibits the proliferation of epithelioid SMCs provides a mechanism to account for the observation in previous studies that hyperglycaemia decreases DNA synthesis in SMCs from balloon-injured arteries of type 1 diabetic rats or rabbits
[17-19]. In response to balloon injury, the neointima will develop under the newly formed endothelium. It is known that cells derived from neointima lesions display an epithelioid phenotype [21]. Therefore, on the basis of our findings, the proliferation of cells contributing to neointima formation could be selectively inhibited by hyperglycaemia. This may be extended from the balloon injury model to atherosclerosis, in which neointima formation is an early event. Therefore, glucose treatment alone may inhibit the development of proliferative vascular diseases.

Second, phenotype-specific effects partially explain the previously published controversial data showing that glucose treatment does not stimulate SMC proliferation [11-14, 42]. The lack of effect of glucose treatment could have been due to the use of spindle-shaped SMCs, because we showed that this cell phenotype was not responsive to high-glucose treatment. In addition, it has been speculated that the mechanism by which high glucose levels stimulates SMC proliferation depends on the animal species from which the SMCs were derived and the different conditions used for cell culture [42]. However, we would favour a hypothesis involving a third SMC phenotype that may have proliferative responses to glucose treatment. Nevertheless, our present study has reinforced the importance of considering the heterogeneity of SMCs in the determination of the direct effects of hyperglycaemia on SMCs in diabetes.

To our knowledge, it has never been reported that glucose treatment inhibits SMC proliferation. We have now revealed that inhibition of SMC proliferation by glucose treatment involves PKC activation and that this effect is also phenotype-specific. Although activation of PKC by glucose treatment could be mediated by the production of diacylglycerol, our data showing that glucosamine mimics the inhibitory effect of glucose treatment on SMC proliferation and that inhibition of glutamine:fructose-6-phosphate aminotransferase reverses this effect strongly suggest involvement of the hexosamine pathway in activation of PKC and the effects of glucose treatment on SMCs. In addition, the increase in ROS production induced by glucose treatment was reported to promote the formation of glucosamine through the hexosamine pathway [43]. Therefore, our data showing that glucose treatment increased the production of ROS in epithelioid SMCs further support the involvement of the hexosamine pathway. These results are also consistent with data in the literature showing that an increase in ROS production concurs with PKC activation in response to glucose treatment [44].

How glucosamine stimulates PKC remains unknown, but our conclusion that the activation of PKC by glucose treatment inhibits SMC proliferation is well supported by previous studies. For example, PDBu and 1,2-dioctanoylglycerol both potently inhibited serum-stimulated DNA 
synthesis and cell population doubling of SMCs [34]. In addition, overexpression of $P K C \delta$ [35] or $P K C \alpha$ [36] inhibits SMC proliferation as well. It is interesting to note that activation of PKC also stimulates SMC proliferation [45]. The different PKC isozymes are thought to have distinct functions regarding the phosphorylation of specific substrate proteins [46]. Evidence to date suggests that each PKC isozyme has a distinct role in the proliferation of nonmuscle cells. For example, overexpression of $P K C \delta$ in $\mathrm{NIH}$ $3 \mathrm{~T} 3$ cells induces inhibition of cell proliferation, but PKC $\varepsilon$ stimulates cell proliferation [47]. In addition, overexpression of $\mathrm{PKC} \alpha$ inhibits proliferation and induces differentiation in melanoma cells [48].

How does activation of PKC inhibit SMC proliferation? It has been shown that the G1/S inhibition is mediated by $\mathrm{PKC} \alpha$ and $\mathrm{PKC} \varepsilon$ [34]. Overexpression of $P K C \delta$ arrests SMCs in G1, mainly by inhibiting the production of cyclin $\mathrm{D} 1$ and cyclin $\mathrm{E}$ and increasing the production of $\mathrm{p} 27$ [35]. However, our study has revealed a novel mechanism involving activation of the MAP kinase pathway and p27 induction. This mechanism is supported by at least two previous studies. First, in mesangial cells, glucose treatment upregulates p27 by activation of the MAP kinase pathway, leading to cell hypertrophy [49]. In addition, the MAP kinase pathway can mediate growth inhibition and proliferation in SMCs depending on the availability of downstream targets [50]. Our previous study showed that activation of the MAP kinase pathway upregulates p27 and arrests the cell cycle of epithelioid SMCs [22]. It has been established that MAP kinases ERK1 and ERK2 phosphorylate p27 at serine(178), increasing its production [49].

Activation of the MAP kinase pathway in response to glucose treatment results in inhibition of SMC proliferation. We have tried to address how glucose treatment stimulates the MAP kinase pathway. Glucose treatment is well known to regulate the expression of growth factors. For example, through metabolism to glucosamine, glucose stimulates the gene expression of $T G F-\alpha[30,31]$. In addition, glucose treatment is reported to enhance the transactivation of EGFR [41], suggesting potential involvement of EGFR in the observed effects of glucose treatment. However, the lack of effect by the EGFR inhibitor AG1478 in our study does not support the hypothesis that the effects of glucose treatment are mediated by upregulation of TGF- $\alpha$ or transactivation of EGFR. Additionally, PKC is well known to phosphorylate and activate RAF, a serine/threonine kinase upstream of MEK [37-40]. Our data showing that the MEK inhibitor PD98059 inhibits the effects of glucose, glucosamine and PDBu support the speculation of crossactivation of Raf, but more studies will be required to confirm this possibility or to investigate other potential mechanism(s).
Finally, our study has raised the question of whether hyperglycaemia has a beneficial effect on proliferative vascular disease. Our in vitro studies cannot address this question. Although epithelioid SMCs have higher proliferation and migration activities, we do not know whether these activities are required for repair or remodelling, for example, after balloon injury. Since the roles of epithelioid cells in atherogenesis have not been established in vivo, we cannot draw a conclusion about whether or not the phenotype-specific effect of glucose treatment contributes to vascular complications of diabetes. However, our present study has provided the first evidence that hyperglycaemia has phenotype-specific effects on vascular SMCs.

Acknowledgements The authors are grateful to $M$. Walsh for providing the laser-scanning cytometer through his Canada Research Chair (Tier 1) fund. This work was supported in part by grants from the Canadian Institutes of Health Research and the Canadian Diabetes Association to X. L. Zheng. X. L. Zheng is the recipient of a New Investigator Award from the Heart \& Stroke Foundation of Canada. D.-Q. Peng is the recipient of a Visiting Scholarship Award from the Chinese Education Ministry.

Conflict of interest statement The authors declare that there is no conflict of interest that would prejudice the impartiality of this scientific work.

\section{References}

1. Ross R, Glomset JA (1973) Atherosclerosis and the arterial smooth muscle cell: proliferation of smooth muscle is a key event in the genesis of the lesions of atherosclerosis. Science 180:1332-1339

2. Dzau VJ, Braun-Dullaeus RC, Sedding DG (2002) Vascular proliferation and atherosclerosis: new perspectives and therapeutic strategies. Nat Med 8:1249-1256

3. Yamamoto M, Acevedo-Duncan M, Chalfant CE, Patel NA, Watson JE, Cooper DR (2000) Acute glucose-induced downregulation of PKC-betaII accelerates cultured VSMC proliferation. Am J Physiol, Cell Physiol 279:C587-C595

4. Begum N, Ragolia L (2000) High glucose and insulin inhibit VSMC MKP-1 expression by blocking iNOS via p38 MAPK activation. Am J Physiol, Cell Physiol 278:C81-C91

5. Yasunari K, Kohno M, Kano H, Yokokawa K, Minami M, Yoshikawa J (1999) Antioxidants improve impaired insulinmediated glucose uptake and prevent migration and proliferation of cultured rabbit coronary smooth muscle cells induced by high glucose. Circulation 99:1370-1378

6. Morishita R, Higaki J, Hayashi SI et al (1997) Role of hepatocyte growth factor in endothelial regulation: prevention of high D-glucose-induced endothelial cell death by prostaglandins and phosphodiesterase type 3 inhibitor. Diabetologia 40: 1053-1061

7. Yasunari K, Kohno M, Kano H, Yokokawa K, Horio $\mathrm{T}$, Yoshikawa J (1996) Possible involvement of phospholipase D and protein kinase $\mathrm{C}$ in vascular growth induced by elevated glucose concentration. Hypertension 28:159-168

8. Yasunari K, Kohno M, Kano H, Yokokawa K, Horio T, Yoshikawa J (1995) Aldose reductase inhibitor prevents hyperproliferation and hypertrophy of cultured rat vascular smooth muscle cells induced by high glucose. Arterioscler Thromb Vasc Biol 15:2207-2212 
9. Hiroishi G, Kobayashi S, Nishimura J, Inomata H, Kanaide $\mathrm{H}$ (1995) High D-glucose stimulates the cell cycle from the G1 to the $\mathrm{S}$ and $\mathrm{M}$ phases, but has no competent effect on the G0 phase, in vascular smooth muscle cells. Biochem Biophys Res Commun 211:619-626

10. Natarajan R, Gonzales N, Xu L, Nadler JL (1992) Vascular smooth muscle cells exhibit increased growth in response to elevated glucose. Biochem Biophys Res Commun 187:552-560

11. Sakakibara F, Hotta N, Koh N, Sakamoto N (1993) Effects of glucose treatment and epalrestat on sorbitol and myo-inositol metabolism in cultured rabbit aortic smooth muscle cells. Diabetes 42:1594-1600

12. Xia P, Kramer RM, King GL (1995) Identification of the mechanism for the inhibition of $\mathrm{Na}^{+}, \mathrm{K}(+)$-adenosine triphosphatase by hyperglycemia involving activation of protein kinase $\mathrm{C}$ and cytosolic phospholipase A2. J Clin Invest 96:733-740

13. Jacot TA, Clemmons DR (1998) Effect of glucose on insulin-like growth factor binding protein-4 proteolysis. Endocrinology 139:44-50

14. Williams B, Gallacher B, Patel H, Orme C (1997) Glucoseinduced protein kinase $\mathrm{C}$ activation regulates vascular permeability factor mRNA expression and peptide production by human vascular smooth muscle cells in vitro. Diabetes 46:14971503

15. Park SH, Marso SP, Zhou Z, Foroudi F, Topol EJ, Lincoff AM (2001) Neointimal hyperplasia after arterial injury is increased in a rat model of non-insulin-dependent diabetes mellitus. Circulation 104:815-819

16. Suzuki LA, Poot M, Gerrity RG, Bornfeldt KE (2001) Diabetes accelerates smooth muscle accumulation in lesions of atherosclerosis: lack of direct growth-promoting effects of high glucose levels. Diabetes 50:851-860

17. Dahlfors G, Chen Y, Gustafsson B, Arnqvist HJ (2000) Inhibitory effect of diabetes on proliferation of vascular smooth muscle after balloon injury in rat aorta. Int J Exp Diabetes Res 1:101-109

18. Bornfeldt KE, Arnqvist HJ, Capron L (1992) In vivo proliferation of rat vascular smooth muscle in relation to diabetes mellitus insulin-like growth factor I and insulin. Diabetologia 35:104-108

19. Schiller NK, McNamara DB (1999) Balloon catheter vascular injury of the alloxan-induced diabetic rabbit: the role of insulinlike growth factor-1. Mol Cell Biochem 202:159-167

20. Hao H, Gabbiani G, Bochaton-Piallat ML (2003) Arterial smooth muscle cell heterogeneity: implications for atherosclerosis and restenosis development. Arterioscler Thromb Vasc Biol 23:1510 1520

21. Walker LN, Bowen-Pope DF, Ross R, Reidy MA (1986) Production of platelet-derived growth factor-like molecules by cultured arterial smooth muscle cells accompanies proliferation after arterial injury. Proc Natl Acad Sci USA 83:7311-7315

22. Gui Y, Zheng XL (2003) Epidermal growth factor induction of phenotype-dependent cell cycle arrest in vascular smooth muscle cells is through the mitogen-activated protein kinase pathway. J Biol Chem 278:53017-53025

23. Blaes N, Bourdillon MC, Daniel-Lamaziere JM, Michaille JJ, Andujar M, Covacho C (1991) Isolation of two morphologically distinct cell lines from rat arterial smooth muscle expressing high tumorigenic potentials. In Vitro Cell Dev Biol 27A:725-734

24. Gui Y, Zheng XL (2006) 2-methoxyestradiol induces cell cycle arrest and mitotic cell apoptosis in human vascular smooth muscle cells. Hypertension 47:271-280

25. Kamentsky LA (2001) Laser scanning cytometry. Methods Cell Biol 63:51-87

26. Darzynkiewicz Z, Bedner E, Li X, Gorczyca W, Melamed MR (1999) Laser-scanning cytometry: a new instrumentation with many applications. Exp Cell Res 249:1-12
27. Zheng XL, Gui Y, Du G, Frohman MA, Peng DQ (2004) Calphostin-C induction of vascular smooth muscle cell apoptosis proceeds through phospholipase D and microtubule inhibition. J Biol Chem 279:7112-7118

28. Robinson JP, Carter WO, Narayanan PK (1994) Oxidative product formation analysis by flow cytometry. Methods Cell Biol 41:437447

29. Rosenkranz AR, Schmaldienst S, Stuhlmeier KM, Chen W, Knapp W, Zlabinger GJ (1992) A microplate assay for the detection of oxidative products using $2^{\prime}, 7^{\prime}$-dichlorofluoresceindiacetate. J Immunol Methods 156:39-45

30. McClain DA, Paterson AJ, Roos MD, Wei X, Kudlow JE (1992) Glucose and glucosamine regulate growth factor gene expression in vascular smooth muscle cells. Proc Natl Acad Sci USA 89:8150-8154

31. Sayeski PP, Kudlow JE (1996) Glucose metabolism to glucosamine is necessary for glucose stimulation of transforming growth factor-alpha gene transcription. J Biol Chem 271:15237-15243

32. Porte D Jr, Schwartz MW (1996) Diabetes complications: why is glucose potentially toxic? Science 272:699-700

33. Toullec D, Pianetti P, Coste H et al (1991) The bisindolylmaleimide GF $109203 \mathrm{X}$ is a potent and selective inhibitor of protein kinase C. J Biol Chem 266:15771-15781

34. Sasaguri T, Kosaka C, Hirata M et al (1993) Protein kinase Cmediated inhibition of vascular smooth muscle cell proliferation: the isoforms that may mediate G1/S inhibition. Exp Cell Res 208:311-320

35. Fukumoto S, Nishizawa Y, Hosoi M et al (1997) Protein kinase C delta inhibits the proliferation of vascular smooth muscle cells by suppressing G1 cyclin expression. J Biol Chem 272:13816-13822

36. Wang S, Desai D, Wright G, Niles RM, Wright GL (1997) Effects of protein kinase $\mathrm{C}$ alpha overexpression on $\mathrm{A} 7 \mathrm{r} 5$ smooth muscle cell proliferation and differentiation. Exp Cell Res 236:117-126

37. Lorenz K, Lohse MJ, Quitterer U (2003) Protein kinase C switches the Raf kinase inhibitor from Raf-1 to GRK-2. Nature 426:574-579

38. Marais R, Light Y, Mason C, Paterson H, Olson MF, Marshall CJ (1998) Requirement of Ras-GTP-Raf complexes for activation of Raf-1 by protein kinase C. Science 280:109-112

39. Kolch W, Heidecker G, Kochs G et al (1993) Protein kinase C alpha activates RAF-1 by direct phosphorylation. Nature 364:249-252

40. Sozeri O, Vollmer K, Liyanage M et al (1992) Activation of the cRaf protein kinase by protein kinase $\mathrm{C}$ phosphorylation. Oncogene 7:2259-2262

41. Konishi A, Berk BC (2003) Epidermal growth factor receptor transactivation is regulated by glucose in vascular smooth muscle cells. J Biol Chem 278:35049-35056

42. Askari B, Renard CB, Bornfeldt KE (2002) Regulation of smooth muscle cell accumulation in diabetes-accelerated atherosclerosis. Histol Histopathol 17:1317-1328

43. Du XL, Edelstein D, Rossetti L et al (2000) Hyperglycemiainduced mitochondrial superoxide overproduction activates the hexosamine pathway and induces plasminogen activator inhibitor1 expression by increasing Sp1 glycosylation. Proc Natl Acad Sci USA 97:12222-12226

44. Inoguchi T, Sonta T, Tsubouchi H et al (2003) Protein kinase Cdependent increase in reactive oxygen species (ROS) production in vascular tissues of diabetes: role of vascular NAD $(\mathrm{P}) \mathrm{H}$ oxidase. J Am Soc Nephrol 14:S227-S232

45. Herbert JM, Clowes M, Lea HJ, Pascal M, Clowes AW (1996) Protein kinase $\mathrm{C}$ alpha expression is required for heparin inhibition of rat smooth muscle cell roliferation in vitro and in vivo. J Biol Chem 271:25928-25935

46. Nishizuka Y (1995) Protein kinase $C$ and lipid signaling for sustained cellular responses. FASEB J 9:484-496 
47. Mischak H, Goodnight JA, Kolch W et al (1993) Overexpression of protein kinase C-delta and -epsilon in NIH 3T3 cells induces opposite effects on growth, morphology, anchorage dependence, and tumorigenicity. J Biol Chem 268:60906096

48. Gruber JR, Ohno S, Niles RM (1992) Increased expression of protein kinase $\mathrm{C}$ alpha plays a key role in retinoic acid-induced melanoma differentiation. J Biol Chem 267:13356-13360
49. Wolf G, Reinking R, Zahner G, Stahl RA, Shankland SJ (2003) Erk 1,2 phosphorylates p27(Kip1): functional evidence for a role in high glucose-induced hypertrophy of mesangial cells. Diabetologia 46:1090-1099

50. Bornfeldt KE, Campbell JS, Koyama H et al (1997) The mitogenactivated protein kinase pathway can mediate growth inhibition and proliferation in smooth muscle cells. Dependence on the availability of downstream targets. J Clin Invest 100:875-885 